\title{
Data Search for Pornographic Content on Twitter Services using National Institute of Standard and Technology (NIST) Method
}

\author{
Vioni Retno Gita Leri \\ Department of Information System \\ Universitas Ahmad Dahlan \\ Yogyakarta of Indonesia
}

\author{
Imam Riadi \\ Department of Information System \\ Universitas Ahmad Dahlan \\ Yogyakarta of Indonesia
}

\begin{abstract}
The development of mobile device technology, especially on social media to interact with two or more people, has become a necessity that cannot be separated from daily life. Twitter is an online social networking and microblogging service that allows its users to send and read text-based messages, Twitter is currently experiencing rapid growth and is popular throughout the world, due to its high popularity, Twitter is often used for various purposes at this time Twitter is the social media with the highest pornographic content contributor. This study will scenario the crime case using the Twitter application that runs on application mobile using the NIST stages related to the topic of cyberporn distribution. The stages of theforensics National Institute of Standards and Technology (NIST)are collection, examination, analysis, and reporting. This study uses a smartphone with a rooted condition and the Twitter application is installed. The crime case scenario in cyberporn this research is the distribution of pornographic content on Twitter based on examples of existing cases. The process of collecting digital evidence through the Twitter API and using two forensic tools, namely MOBILedit forensic express and SQLite. This study produces digital evidence in the form of account information, posts or tweets that have been deleted including text, images and videos from smartphone a rooted.The results of the evidence obtained will be given to the court if needed, to assist in the law enforcement process to uncover digital crime cases.
\end{abstract}

\section{Keywords}

Forensics, Cellular, Twitter, Cyberporn, NIST

\section{INTRODUCTION}

The development of information technology, especially social media which is used to interact with two or more people, done online has become a necessity that cannot be separated from everyday life. One of the social media that is often used by the public is Twitter [1]. In cyberspace, it is not possible to regulate someone to post or publish content, but content that is harmful or contains something that can trigger public unrest can be reported, people who are restless and feel aggrieved by posts that are spread, report to the authorities. Many examples of cases that are often reported such as pornography, cyberbullying, defamation, fraud and many more cases of crime in cyberspace. Computer crime is a crime whose traces of criminal activity need to be analyzed to become evidence [2]. Such crimes can be uncovered with the help of digital forensics. One of the steps to assist investigators in conducting digital forensics is the NIST stage. The NIST stage is used to obtain information from digital evidence [3].
There are several stages in the NIST method, namely collection, examination, analysis, and reporting [4].

\subsection{Study Literature \\ 1.1.1 Previous Study}

Rusydi and Sahiruddin (2019) has conducted a digital forensic research entitled "NIST Method for Forensic Analysis of Digital Evidence on Android Devices".In this study, it describes the forensic process that is running to get back digital evidence in the form of deleted data on ansmartphone androidusing the Wondershare dr. Fone for Android, Oxygen Forensic Suite 2014 to prove crimes at trial. It can be concluded: to find digital evidence in the form of contact data, logs call, and messages that have been deleted on thesmartphone, Samsung Galaxy J1 Aceit can be concluded that recovery with the Wondershare tool only reaches $30 \%$, while the results of recovery with Oxygen forensics reach $73 \%$ of deleted data. can be returned. Therefore, the data recovered from digital evidence with thetool is Oxygenhighly recommended as evidence in proving criminal cases in court. [5].

Ermadi Satriya Wijaya and Teguh Subagyo (2017) have conducted a digital forensic research entitled "Analysis of Digital Evidence on Random Access Memory AndroidUsingMethods in Live Forensic Child Abduction Cases", it can be concluded: this study scenarios the process of disclosing digital evidence in child abduction cases., in the process of proving this research managed to find digital evidence in the form of pictures sent by the perpetrator, previously deleted text messages and log files of incoming calls on the victim's smartphone and log file of outgoing calls on thesmartphone perpetrator's, but there were some data that could not be found such as time and voice calls [6].

Fadillah, Noor, Umar, and Yudhana (2018) have conducted a digital forensic research entitled "The Design of the NIST Method for Forensic Mobile Payment AndroidBasedApplications". This research can be concluded that the process of removing digital evidence from a smartphone that has aapplication installed mobile payment requires rooting for ansmartphone Android, and there are many tools that can be used in the process of removing digital evidence that runs on the Windows platform. [7].

Prasongko, Yudhana, and Fadil (2018) have conducted a digital forensic research entitled"Forensic Analysis of Kakaotalk Applications Using the NIST Method". In this study, conclusions can be drawn: This study uses the NIST Mobile Forensic method and research tools to perform forensic analysis on the KakaoTalk application. During the 
process of removing digital evidence from KakaoTalk, rooting for Android smartphones is required. Digital evidence is expected from the appointment process and forensic analysis can help the process of investigating a digital crime [8].

Imam and Nurhairani (2019) have conducted digital forensic research entitled "Analysis of Mobile Forensics on Twitter Application using the National Institute of Justice (NIJ) Method. This study discusses the Twitter application for handling cybercrime containing hate speech in direct messengers or secret chats, the conclusions obtained are: the results of forensic evidence research obtained using the stages of the method NIJ, identification, collection, examination, analysis, reports using smartphone rooted with DB Browser for SQLite, SQLite Manager, Root Explorer, evidence that can be found 2 user participants, 3messages chat and 1 picture, location, and profile of the perpetrator while a smartphone with condition non-root only gets 1 file APK[9].

\subsubsection{Digital Forensics}

Digital forensics is the science of identifying evidence from digital sources and provides forensic experts with powerful tools and techniques to solve complex digital-related crimes [10]. Digital Forensics is also a science computertechnology, for proving a crime - a high-tech [11].Forensic methods are an important factor that supports a more effective and efficient crime investigation in handling a case [12]. The purpose of forensics is to obtain the value of evidence. Digital or electronic evidence consists of information and value data stored or transmitted by digital devices [13].

\subsubsection{Mobile Application}

application mobile comes from two words, and applications. mobile terms, an application is a ready-made program that is made to carry out a function for another user or application, while mobile is a movement from one place to another [14]. applications Mobile are software that runs on devices mobile such as smartphones or Tablet PCs.applications are Mobile also known as applications that can be downloaded and have certain functions that add to the functionality of the device mobile itself, to get mobile application the desired, users can download it through certain sites according to their operating systems such as Google Play and iTunes.

\subsubsection{Digital Evidence}

evidence is generally related to digital crimes such as crimes that use social media as a place to commit crimes, so digital evidence is used to assist in prosecuting all types of digital crimes [15]. Digital evidence is included in Law no. 11 of 2008 concerning Information and Electronic Transactions. Digital evidence is so susceptible to alteration that it can affect its authenticity if not handled properly. Any kind of alteration that contains digital evidence will lead to wrong conclusions, or the evidence will be useless [16]. Digital evidence requires a standardized and formalized process so that digital evidence can be accepted during the trial process [17].Digital evidence is divided into 15 types, namely logical files, encrypted audio files, deleted files, video files, emails,images files, user id / password, etc [18].

\subsubsection{Twitter}

Twitter is a social networking service as well as microblog online, Twitter is a medium of communication, information, news, motivation, business, media for driving and influencing the masses, entertainment media in spare time, and honing writing skills. On Twitter users can also upload other media besides text such as images and videos called tweet pic [19]. Tweets themselves can consist of messages, text, and photos.
Apart from that, tocompose messages based on topic users can also use the \# sign (hashtag) [20].The Twitter service also provides a Twitter API which is used to get information. API stands for Application Programming Interface, API allows users to manage Twitter information that users have previously been allowed to do.

\subsubsection{Cybercrime}

Cybercrime is a crime that uses information technology as a crime target, and digital forensics is basically, answering the questions: when, what, who, where, how, and why related to digital crime. The misuse of social media and instant messaging in mobile services allows cybercriminals to take advantage of these services for malicious purposes [21]. There are many types of cybercrime: one example is cyber pornography, the term refers to the use of information technology to create, display, distribute, publish pornography and obscene material in the form of text, photos, and videos.

\subsubsection{National Institute of Standard Technology}

This is a forensic stage that has policy work guidelines and standards to ensure each examiner follows the same workflow so that work is documented and the results can be repeated and can be maintained, this stage will assist investigators in conducting digital forensics. The stages in NIST are collection, examination, analysis, and reporting [22]. The stages can be seen in Figure 1.

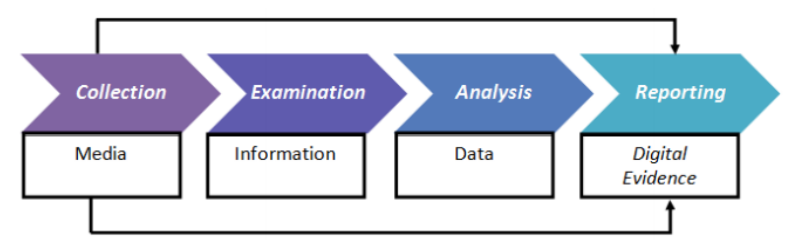

Figure 1. The stages of NIST

1. Collection

Collection is labeling, identification, recording, and retrieval of data from relevant data sources with the following procedures to maintain data integrity.

2. Examination

Examination is a process to protect evidence from damage and alteration by parties who are not responsible for the process collection in collecting electronic evidence and analyzing electronic data by forensic experts.

3. Analysis

Analysis is the analysis of the results of the examination using technically justified methods and the law.

4. Reporting

Reporting is reporting the results of the analysis which includes the description of the actions taken.

\subsubsection{Pornography}

Pornography is all forms of audio, visual, and audio-visual material that is in a sexual context in the form of writing, pictures, video shows that focus on the genitals and sexual behavior for sexual gratification and pleasure. One factor in the development of the spread of pornographic content is the increasingly advanced technology, especially the internet [23]. Based on the Law of theIndonesia number 44 of 2008 concerning pornography, it is stated in article 1 paragraph 1 that pornography is pictures, sketches, illustrations, photos, writings, sounds, sounds, moving images, animations, cartoons, conversations, gestures, or other forms of messages. through various forms of communication media or public 
performances, which contain obscenity or sexual exploitation that violates the norms of decency in the society.

\section{METHODOLOGY}

\subsection{Research Scenario}

This scenario is created to explain how the stages of the mobile application forensic process will be carried out. The case scenario in this research is the spread of pornographic content on Twitter using a smartphone, so that on Twitter, many quick views, comments, and even re-post the tweet retweeting or commonly known as. The video is being seen and distributed more and more, people who feel restless or feel aggrieved by this report to the authorities, after the user or account owner finds out that the video is viral, the user intentionally deletes his post on Twitter to eliminate evidence.

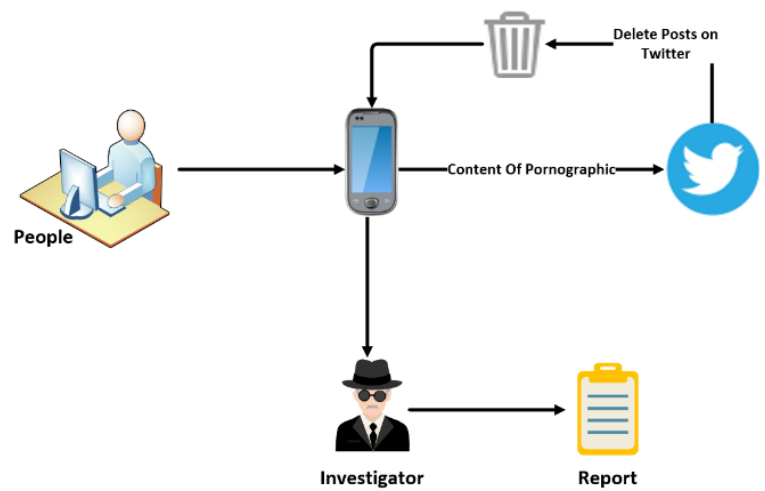

Figure 2. Simulation of the Research Scenario

Figure 2 explains after the suspect is caught, evidence will be confiscated in the form of a smartphone suspected of spreading pornographic content to Twitter, then it will be handed over to the Investigator team to investigate the case by investigating the perpetrator's smartphone.

The investigator process will collect digital evidence through the Twitter API and carry out a forensic process using forensic tools that have been prepared previously to obtain digital evidence. The results of the evidence obtained will be given to the court if needed.

\subsection{Research Stages}

The NIST forensic stage is a forensic stage that has policy work guidelines and standards to ensure each investigator follows the same workflow so that work is documented and the results obtained can be repeated and can be maintained. At this stage, the investigator team conducts an investigation process to obtain information. The stages or methods used to obtain digital evidence include collection, examination, analysis, and reporting.

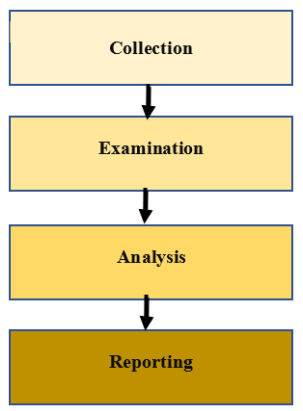

Figure 3. Stages of Research Implementation
In Figure 3 are the stages of NIST implementation. This investigative model is used to find digital evidence to find evidence facts cyberporn that occurs on the Twitter application. The steps that will be taken by the investigator team in finding and collecting digital evidence are explained as follows:

\subsubsection{Collection}

Collecting evidence from the Twitter API and through the R Studio application managed to get Twitter data in CSV format. Other evidence that was successfully obtained was a smartphone, as can be seen in Table 1 .

Table 1. Physical Evidence Found

\begin{tabular}{|l|l|l|l|}
\hline No. & Name & \multicolumn{1}{|c|}{ Image } & Description \\
\hline 1 & $\begin{array}{c}\text { The } \\
\text { smartphone } \\
\text { perpetrator's } \\
\text { front view } \\
\text { of the }\end{array}$ & $\begin{array}{c}\text { Samsung } \\
\text { Galaxy Grand } \\
\text { Prime brand, is } \\
\text { on, connected } \\
\text { to the network, } \\
\text { and in a root } \\
\text { state }\end{array}$ \\
\hline 2 & $\begin{array}{c}\text { Smartphone } \\
\text { behind-the- } \\
\text { scenes }\end{array}$ & \\
\hline
\end{tabular}

The evidence collected will be subject to an acquisition process to view and search for digital evidence on data smartphone stored in the database smartphone.

\subsubsection{Examination}

At this stage the process of transferring or retrieving information obtained from the smartphone perpetrators and maintaining the authenticity and integrity of the data. The way to protect digital evidence is by hashing electronic data that has been successfully backed up. The initial hashing results and the final hashing results will be matched to determine the authenticity of the data from the digital evidence obtained. The process of hashing the file CSV from the Twitter API, software MOBILedit, and SQlite using the software tool, the first process step is to copy the original folder from the backup data.

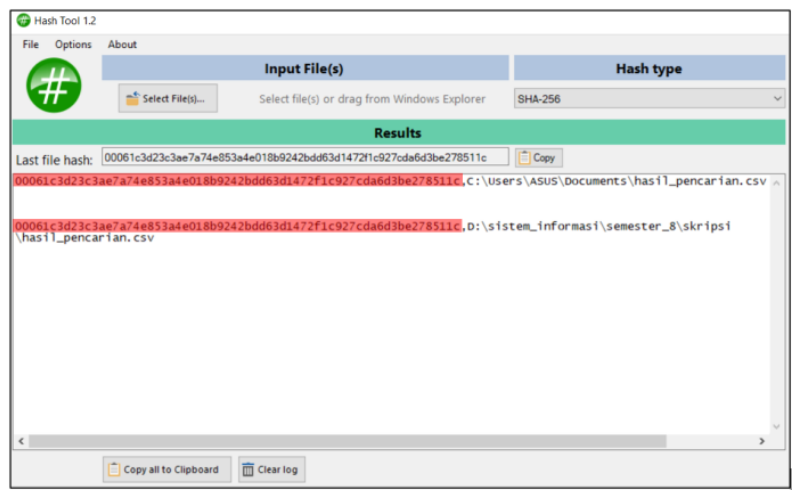

Figure 4. Twitter API File Hashing Results

Figure 4 is the display of hashing results on the Twitter API file, the red color shows the encryption code file Twitter API, from the row of words the encryption code remains the same, which means that no data changes have occurred. 


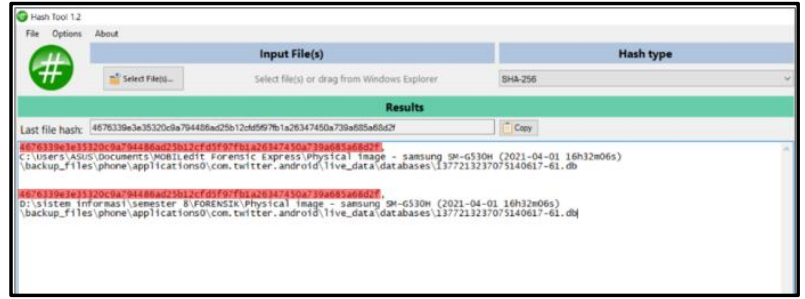

Figure 5. Results of HashingData Backup Files Smartphone

Figure 5 shows the results of hashing the backup data from MOBILedit, the red color shows the file encryption code, from the row of words the encryption code remains the same meaning no data changes have occurred.

\subsubsection{Analysis}

The analysis, the stage is the process of searching for information in the form of digital evidence from data extracted from the Twitter API and acquisitions smartphone previous. The information sought is account information, tweets that have been deleted in the form of text, images, and videos. Analysis of the results of the examination using the Twitter API and forensic tools MOBILedit forensic express, and SysTools SQLite Viewer.

\subsubsection{Twitter API}

Limitations of using the Twitter API if the investigation team collects data for more than one week from the user posting tweets then the evidence data cannot be found due to limited access and if the user has deleted the tweets on his Twitter account then the investigation team cannot find digital evidence in Twitter API, because the simulation case in this study tells about a user intentionally uploading or distributing pornographic content to Twitter and intentionally deleting the content because the content has gone viral and was reported by the public, therefore collecting evidence from the Twitter API is not prioritized.

\subsubsection{MOBILedit Forensic}

The data acquisition process begins by analyzing the previously created image. Twitter application options will appear, as in the existing application options.

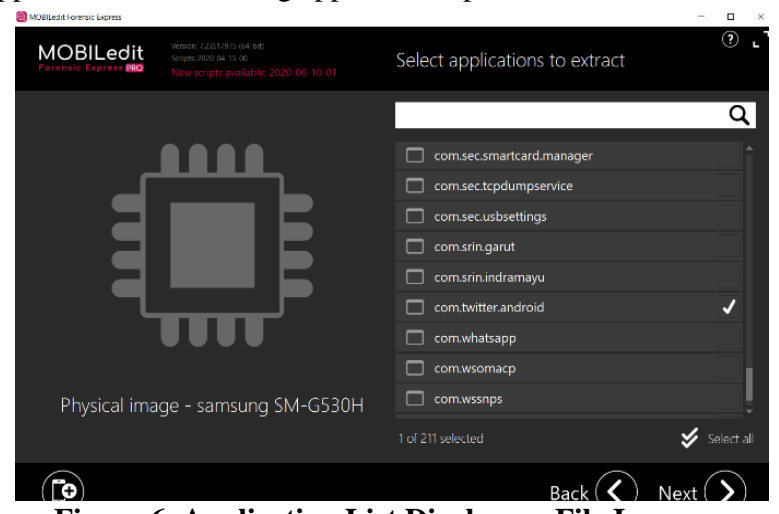

Figure 6. Application List Display on File Image

Figure 6 is a list of applications from which the then investigator selects the Twitter application to extract data, the Twitter application is stored in the com.twitter.android directory and performs data extraction.

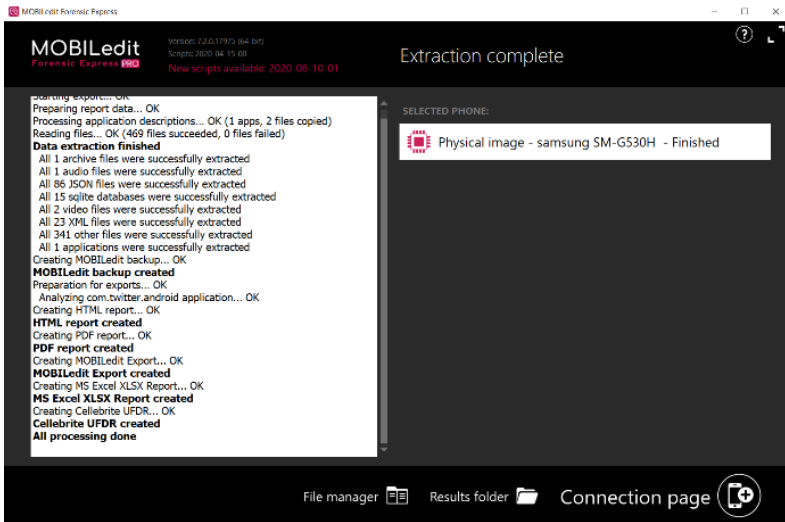

Figure 7. Display of the Data Extraction Process

Figure 7 the display of the data extraction process for the Twitter application installed on the smartphone. The results of data extraction on the smartphone will be stored automatically in the form of reporting or reports.

\subsubsection{SysTools SQLite Viewer}

Stages of the analysis process to find and obtain digital evidence stored in the smartphone database perpetrators using the SysTools SQLite Viewer tool. In the initial screen select the open database, open the database with the name 1377213237075140617-61.db then open the browse data menu, in the table column select the users table which includes id, user_id, username, name, image_url, user flags, friendship, friendship_time, header_url, description, location, url_entities, web_url, link_, fast_followers, friends, statuses, favorites, media_, updated, and others whose more complete details can be seen in the image below.

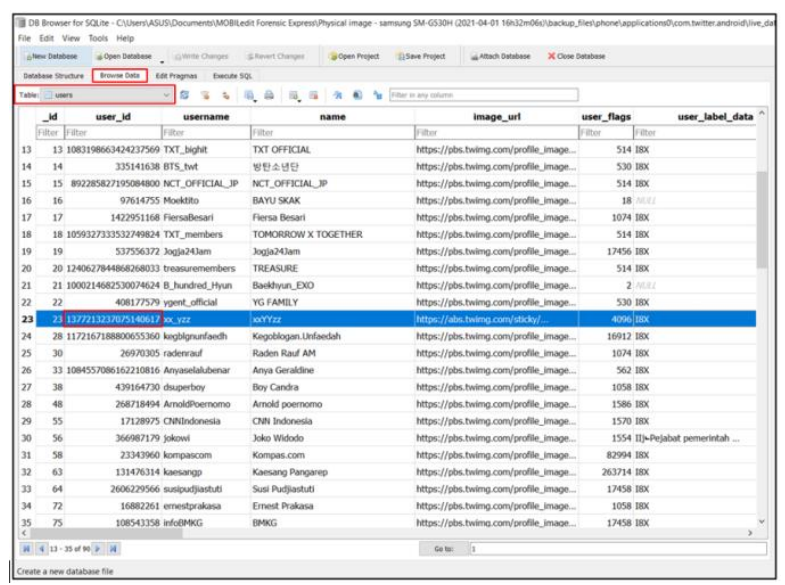

Figure 8. Display of User Results Table

Figure 8 is the results of Table users, there are names of Twitter users stored in the database, one of which is a Twitter account that posts pornographic content to Twitter.

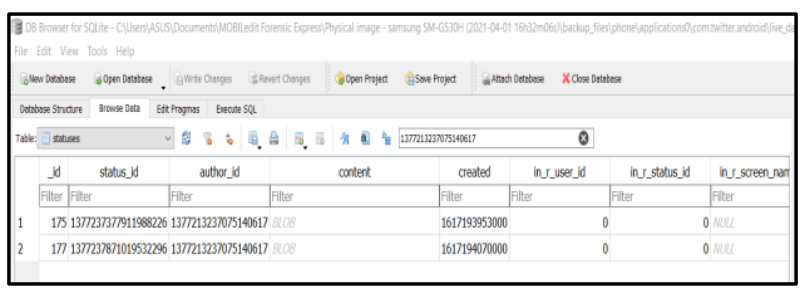

Figure 9. Display of Statuses Table Results 
In Figure 9 are the results of TableStatuses, Statuses is the name of the table in the databases and there is evidence of posts from Twitter users who post pornographic content.

\subsubsection{Reporting}

Reporting is the final stage that aims to present the data from the analysis that has been found by the investigator. Reporting the results of searching for evidence from the software $\mathrm{R}$ Studio and collecting digital evidence from the tool MOBILedit forensic express and SysTools SQLite Viewer

\subsubsection{Twitter API}

Reporting results from the Twitter API directly occurs feature extraction (Tokenizing, Filtering, Stemming, Tagging) through R Studio software which produces CSV files which can be seen in Figure 10.

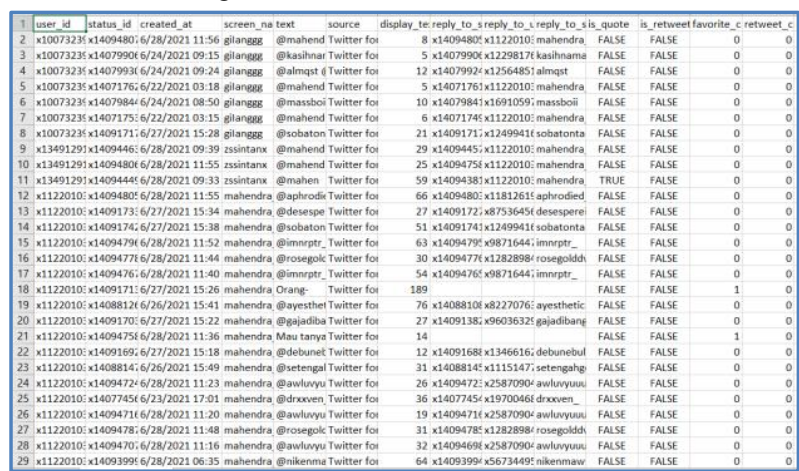

Figure 10. Results of extraction features through R Studio

It was explained in the case simulation that the perpetrator had deleted the post on his personal Twitter account, due to limitations using the Twitter API, so the investigation team did not find digital traces and even digital evidence in this data.

\subsubsection{MOBILedit Forensic}

The file report will be issued after the data extraction process is complete. The contents of the file reporting PDF form show information on device specifications smartphone account information user, and tweets that were deleted by the perpetrator and successfully recovered by the tool MOBILedit.

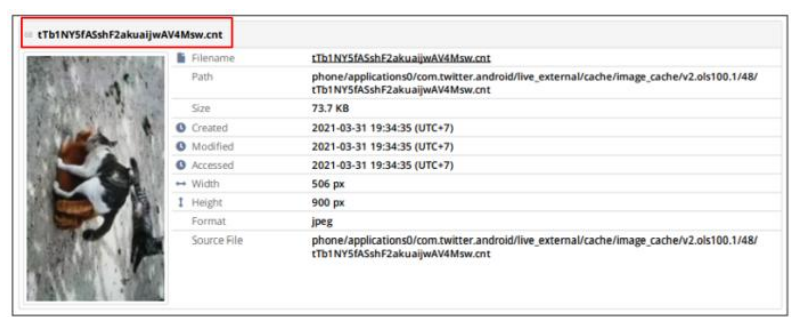

Figure 11. Deleted Image Files on Smartphone

Figure 11 is a deleted file image, there is some information such as filename, format, size, created, modified, accessed, width, height, and source files.

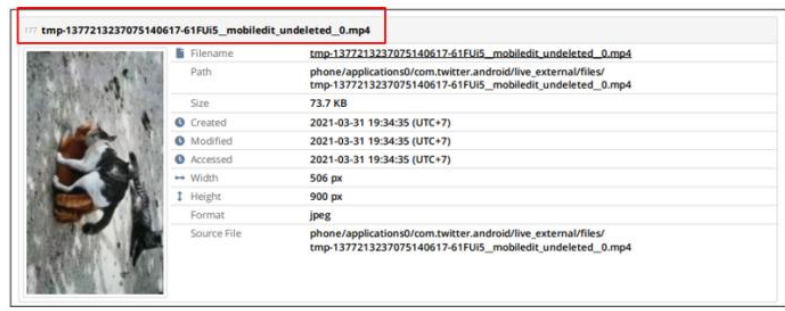

Figure 12. Deleted Video Files on Smartphone

Figure 12 is a deleted file video, there is some information such as filename, path, size, created, modified, accessed, width, height, and source file. There is a difference in the format file in the image above namely, file image with CNT format which means a file to help save different topics for help documents for Windows applications, because for case analysis this research uses a laptop with a Windows operating system, while the video format uses a Windows operating system. MP4 formats.

\subsubsection{SysTools SQLite Viewer}

The process for obtaining evidence by performing analysis stored in the database local smartphones. Figure 9 shows the results of the search the statuses table, when the column is contentclicked, the results will appear.

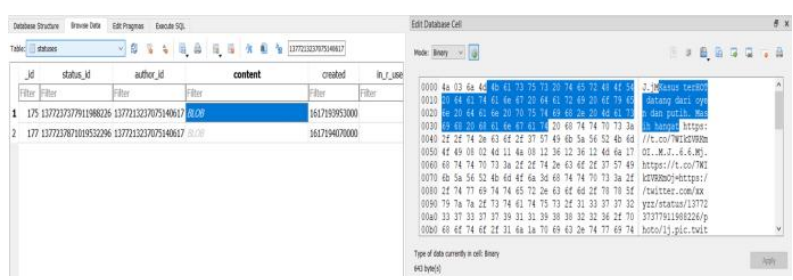

Figure 13. Results of Deleted Photo Tweets

Figure 13 shows the results of posting tweets deleted photo, data has been recovered in the form of proof of account information, profile photos, and image \& video URLs along with the location of the folder that stores the data.

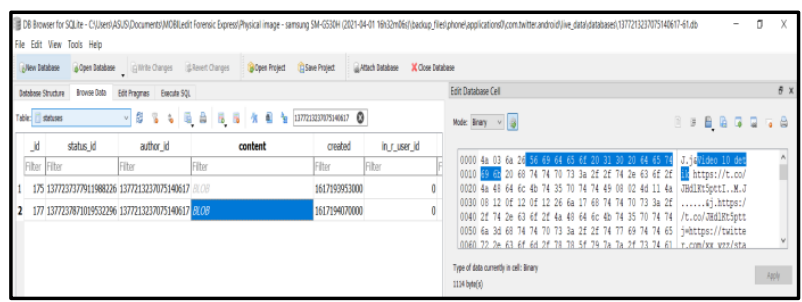

Figure 14. Results of Deleted Video Tweets Posts

Figure 14 shows the results of posting tweets video that has been deleted, data has been recovered in the form of proof of account information, profile photos, and image \& video URLs along with the location of the folder that stores the data. In the picture above is a data extraction process using binary data, and to make it easier to read the data is also provided in hexadecimal form.

\subsubsection{Results}

Tools are tools used to help obtain digital evidence. The evidence obtained from tools forensics can be seen from the comparison table below in Table 2 . 
Table 2. Comparison of Results obtained from Several Tools

\begin{tabular}{|l|c|c|c|}
\hline \multirow{2}{*}{ Information } & \multicolumn{3}{|c|}{ Data/Software/tools } \\
\cline { 2 - 4 } & $\begin{array}{c}\text { Api } \\
\text { Twitter } \\
\text { / R } \\
\text { Studio }\end{array}$ & $\begin{array}{c}\text { MOBILedit } \\
\text { forensic } \\
\text { express }\end{array}$ & $\begin{array}{c}\text { SysTools } \\
\text { SQLite } \\
\text { Viewer }\end{array}$ \\
\hline $\begin{array}{l}\text { Recover deleted } \\
\text { tweet data }\end{array}$ & $x$ & $\checkmark$ & $\checkmark$ \\
\hline $\begin{array}{l}\text { Limited data } \\
\text { taken }\end{array}$ & $\checkmark$ & $x$ & $x$ \\
\hline $\begin{array}{l}\text { Limited time for } \\
\text { data collection }\end{array}$ & $\checkmark$ & $x$ & $x$ \\
\hline $\begin{array}{l}\text { Get account } \\
\text { information after } \\
\text { content is deleted }\end{array}$ & $\times$ & $\checkmark$ & $\checkmark$ \\
\hline
\end{tabular}

Based on the results of the comparison table above, it produces information to recover deleted tweets data by using 2 tools, namely MOBILedit and SQLite. Data retrieval is not possible from the Twitter API due to the limitations of the data taken and the limited time of data retrieval, to get account information after the content is deleted, you can use 2 forensic tools, namely MOBILedit and SQLite, while Twitter API cannot get information that has been deleted.

Table 3. The original evidence obtained

\begin{tabular}{|c|c|c|c|c|c|}
\hline \multicolumn{5}{|c|}{ The results found from the imaging data } \\
process \\
\hline Name & $\begin{array}{c}\text { User } \\
\text { Information }\end{array}$ & Text & $\begin{array}{c}\text { Picture/ } \\
\text { Photo }\end{array}$ & Videos & $\begin{array}{c}\text { Profile } \\
\text { Picture }\end{array}$ \\
\hline $\begin{array}{l}\text { Digital } \\
\text { evidence } \\
\text { obtained }\end{array}$ & $\checkmark$ & $\checkmark$ & $\checkmark$ & $\checkmark$ & $\checkmark$ \\
\hline
\end{tabular}

In table 3 is a record of digital evidence that was found, in the form of account information, text, photos, videos in tweets, and user profile photos.

\section{CONCLUSION}

Digital evidence can be found through the Twitter API to help collect digital evidence, but due to limited access, investigations through the Twitter API are not the main focus of searching and collecting evidence in this study. The collection of evidence is focused on the perpetrator's smartphone. Postings that have been deleted on the Twitter app can be restored after a process root on smartphones actors and process imaging smartphone using tools MOBILedit express forensic and seek evidence digital smartphone database using SysTools SQLite Viewer tool. The results of digital evidence found in the form of account information, posts, or tweets that have been deleted include text, images, and videos.

\section{REFERENCES}

[1] T. E. Damayanti, "Utilization of Twitter as Media Information Sharing in Libraries (Case Study About Utilization of Social Media Twitter as Media Information Sharing in Libraries of City 2Surabaya)."

[2] I. Riadi, S. Sunardi, and A. A. Kadim, "Monitoring of Mobile Native Application Logs Using the Grr Rapid Response Framework," J. Buana Inform., vol. 10, no. 1, p. 1, 2019, doi:10.24002/jbi.v10i1.1909.

[3] D. Hariyadi, U. Jenderal, and A. Yani, "Identification of
Conversation Evidence on the Dual Apps Whatsapp Application," no. November, 2018 doi:10.13140/RG.2.2.20253.56805

[4] I. Riadi, R. Umar, and I. M. Nasrulloh, "Digital Forensic Analysis on Frozen Solid State Drives Using the National Institute of Justice (NIJ)," MethodElinvo (Electronics, Informatics, Vocat. Educ., vol. 3, no. 1, pp. 70-82, 2018, doi: 10.21831/elinvo.v3i1.19308.

[5] R. Umar and Sahiruddin, "Nist Method For Forensic Analysis of Digital Evidence On Android Devices," Pros. SENDU_U_2019, p. 978-979, 2019.

[6] E. S. Wijaya, "Analysis of Digital Evidence on Android Random Access Memory Using the Live Forensic Method of Child Abduction Cases," Media Pratama Journal, pp. 1-11, 2017.

[7] M. N. Fadillah, R. Umar, and A. Yudhana, "Design of the Nist Method for Forensic Android-Based Mobile Payment Applications," Semin. Nas. Inform. 2018 (semnasIF 2018), vol. 2018, no. November, pp. 115-119, 2018, [Online] Available at: http://jurnal.upnyk.ac.id/index.php/semnasif/article/view/ 2626.

[8] R. Y. Prasongko, A. Yudhana, and A. Fadil, "Forensic analysis of the KakaoTalk application using national institute s method standard technology," Semin. Nas. information. 2018 (semnasIF 2018) UPN "Veteran" Yogyakarta, 24 Novemb. 2018 ISSN 1979-2328, vol. 2018, no. November, p. 129-133, 2018.

[9] H. Nurhairani and I. Riadi, "Analysis of Mobile Forensics on Twitter Application using the National Institute of Justice (NIJ) Method," Int. J. Comput. app., vol. 177, no. 27, p. 35-42, 2019, doi:10.5120/ijca2019919749.

[10] B. Carrier, "Open \{Source $\}$ \{Digital $\} \quad\{$ Forensics $\}$ \{Tools\}: \{The\} \{Legal\} \{Argument\}," no. October, 2002.

[11] S. Pambayun dan I. Riadi, "Investigation on Instagram Android-based using Digital Forensics Research Workshop Framework," Int. J. Comput. Appl., vol. 175 , no. 35, hal. 15-21, 2020, doi: 10.5120/ijca2020920904.

[12] R. Umar, A. Yudhana, and M. Nur Faiz, "Performance Analysis of Live Forensics Methods for Random Access Memory Investigations in Proprietary Systems," Pros. conf. Nas. The 4 Asos. program. Postgraduate. teacher. Muhammadiyah High, no. June 2016, p. 207-211, 2016.

[13] R. Montasari, "Review and Assessment of the Existing Digital Forensic Investigation Process Models," Int. J. Comput. Appl., vol. 147, no. 7, pp. 1-9, 2016.

[14] Buyens, Jim. 2001. Web Database Development. Elex Media Komputindo. Jakarta

[15] I. Riadi, R. Umar, and A. Firdonsyah, "Identification of Digital Evidence on Android's Blackberry Messenger Using NIST Mobile Forensic Method," Int. J. Comput. science. inf. Secur., vol. 15, no. 5, p. 3-8, 2017.

[16] I. Publication, "International Journal of Computer Science and Information Security (IJCSIS)," Int. J. Comput. science. inf. Secur. IJCSIS, vol. 9, no. 6, p. 355, 2011, [Online]. Available at http://sites.google.com/site/ijcsis/. 
[17] M. S. Ahmad, I. Riadi, and Y. Prayudi, "A Live Forensic Investigation from the User's Side to Analyze Man in the Middle Attack Attacks Based on Evil Twins," Ilk. J. Ilm., vol. 9, no. 1, p. 1-8, 2017, doi:10.33096/ilkom.v9i1.103.1-8.

[18] T. Pandela and I. Riadi, "Browser Forensics on Webbased Tiktok Applications," 2020.

[19] P. W. Setyaningsih, Y. Prayudi, and B. Sugiantoro, "Management of Digital Evidence from the Acquisition of Dfxml," J. Tek. information., vol. 11, no. 1, p. 47-54, 2018, doi:10.15408/jti.v11i1.6680.

[20] R. Saputra dan I. Riadi, "Forensic Browser of Twitter based on Web Services," Int. J. Comput. Appl., vol. 175, no. 29, hal. 34-39, 2020, doi: 10.5120/ijca2020920832.

[21] M. N. Faiz, R. Umar, and A. Yudhana, "Analysis of Live Forensics for Comparison of Email Security on Proprietary Operating Systems," Ilk. J. Ilm., vol. 8, no. 3, p. 242-247, 2016, doi:10.33096/ilkom.v8i3.79.242-247.

[22] A. Yudhana, I. Riadi, and I. Anshori, "Analysis of Digital Evidence for Facebook Messenger Using the Nist Method," It J. Res. Dev., vol. 3, no. 1, p. 13-21, 2018, doi:10.25299/itjrd.2018.vol3(1).1658.

[23] Raka, Z. D, "4523/Kom-D/Sd-S1/2021 Analysis of P3Sps Violations on Bigo Live Application Shows," 2021. 